\title{
Vulvar Carcinoma Survival Outcome: An Institutional Experience
}

\author{
Rajshree Dayanand Katke ${ }^{1 *}$, T0 Kothari ${ }^{2}$ and Mahesh S Rewadkar \\ ${ }^{1}$ Obstetrics \& Gynaecology, JJ group of Hospitals, India \\ ${ }^{2}$ Oncology Department, Cama \& Albless Hospitals, India
}

Submission: December 12, 2017; Published: January 04, 2018

"Correspondence Address: Rajshree Dayanand Katke, Professor and Unit Head, Obstetrics \& Gynaecology, Grant Govt Medical College \& JJ group of Hospitals Superintendent, Cama and Albless Hospitals, Mumbai-01, Tel: +919869917830; Email: drrajshrikatke@gmail.com

\section{Introduction}

Clinical management of malignant lesions of vulva implies several challenges for the treating gynecologist and an oncologist. A recently decreasing trend of vulvar cancer are reported over last 24 years - the incidence has decreased from $2.25 \%$ between 1984 and 1988, down to $0.33 \%$ between 2004 and 2008 and the median age being 65-70 [1]. While if talking in terms of the global data the incidence of vulvar cancer has increased by $20 \%$ between 1973 to 2000 and there is also a decrease in the median age of presentation [2].

The major risk factors for the development of vulvar cancer include increasing age, smoking, immunosuppressive disease and chronic skin diseases of the vulva such as lichen sclerosus, VIN, erythroplasia of queyrat but these trends can most likely be attributed to an increasing number of human papillomavirus (HPV) infections. Therefore, with increasing incidence of HPV infection younger and sexually active women are increasingly being affected thus shifting the treatment trends are towards reduced radicality of the surgeries [3].

In contrast to preinvasive lesions (vulvar intraepithelial neoplasia [VIN]) and micro invasive carcinoma ( $\leq 2 \mathrm{~cm}$ size and $\leq 1$ $\mathrm{mm}$ stromal invasion, International Federation of Gynecology and Obstetrics [FIGO] stage IA), surgical management of vulvar cancer from FIGO stage IB includes groin surgery in addition to local tumor resection according to current treatment recommendations with most commonly used method being triple incision technique. In addition to surgery, radiotherapy and chemotherapy are the additional or alternate treatment modalities for the management of vulvar cancer, especially for locally advanced and metastatic disease.

For the purposes of primary treatment, various guidelines provide treatment recommendations by clinical stage, separating patients into those with early-stage (stage I/II), locally advanced (stage III/IVA), and distant metastatic disease (stage IVB, beyond the pelvis). Patients with early-stage disease include those with
$\mathrm{T} 1$ or smaller T2 primary tumors; smaller T2 primary tumors are classified as $\leq 4 \mathrm{~cm}$ with no/minimal involvement of the urethra, vagina, or anus [4]. This institutional review aims outline the current scenario with regard to vulvar cancer with respect to the incidence in our institute, and the modalities used for management and the related results that were obtained in the form of disease specific overall survival, disease free survival and a few other parameters.

\section{Materials and Methods}

This is a retrospective cohort study of cases diagnosed as vulvar cancer in the Cama and Albless Hospital, JJ Group of Hospitals, Mumbai from Jan 2013 to October 2017. Hospital records from the Department of Obstetrics and Gynaecology and the Department of Radiotherapy were studied [5]. Twenty patients with histologically proven diagnosis of vulvar cancer were included in the analysis. The presence of risk factors, stage of disease, treatment modalities used, and disease outcomes in terms of complications and survival were tabulated. The data thus collected were analyzed and compared with the published literature.

\section{Results}

Tables 1 \& 2 (Figures 1-5) In an audit of twenty cases, one was Stage I, 5 were Stage II, 7 were Stage III, and 7 were Stage IV. Age ranged from 50 to 81 years (median 63 years). Patients with performance status of ECOG $\leq 2$ at the time of presentation were only included. Ten patients had a P.S of ECOG 0, 7 were ECOG 1, 3 were ECOG 2. Eight patients underwent surgery (wide local excision 3 and radical vulvectomy 5) A few patients were not willing for surgery and a few other were medically unfit for surgery. Six patients received PORT, 5 received palliative RT (concurrent CT+RT in 3), and 7 underwent definitive RT (4 of them received concurrent chemotherapy) [6]. Median follow-up period was 23 months (range 2 - 56months). The 5 -year OS for all stages was $61 \%$. FIGO stage and pathological node positivity were statistically significant prognostic factors for survival. 


\section{Cancer Therapy \& Oncology International Journal}

Table 1: Patient Characteristics- In terms of socioeconomic status of the patients were equally distributed between middle and lower socioeconomic strata.

\begin{tabular}{|c|c|}
\hline Patient characteristic & Value \\
\hline Median Age & 63years (Range 50 to 81 years) \\
\hline \multirow{3}{*}{ Performance status } & ECOG $0=10$ \\
\hline & ECOG $1=7$ \\
\hline & ECOG $2=3$ \\
\hline \multirow{2}{*}{ Socioeconomic status } & Middle $=9$ \\
\hline & Lower $=11$ \\
\hline \multirow{4}{*}{ Associated predisposing factor } & Lichen sclerosus $=3$ \\
\hline & VIN $=6$ \\
\hline & Bowen's $=0$ \\
\hline & Erythroplasia of queyrat $=0$ \\
\hline \multirow{2}{*}{ Clinical Features } & Pruritus $=17$ \\
\hline & Palpable inguinal $\mathrm{LN}=10$ \\
\hline \multirow{3}{*}{ Clinical Stage } & Stage $\mathrm{I} / \mathrm{II}=8$ \\
\hline & Stage III $/$ IVA $=9$ \\
\hline & Stage IVB $=3$ \\
\hline
\end{tabular}

Table 2: Treatment parameters.

\begin{tabular}{|c|c|c|c|c|c|}
\hline \multicolumn{2}{|c|}{ Therapy } & No. of cases & FIGO Stage & $\begin{array}{c}\text { Median survival } \\
\text { (Months) }\end{array}$ & Lost to follow up \\
\hline \multirow{3}{*}{ Surgery } & WLE & 3 & I & Not reached & - \\
\cline { 2 - 6 } & Radical vulvectomy & 5 & II/III & 28 & - \\
\hline RT & & 7 & II/III/ Iva \& b & 28 & 25 \\
\hline CT+RT & & 9 & II/III/IVa \& b & - & - \\
\hline CT & & 0 & -- & & \\
\hline
\end{tabular}

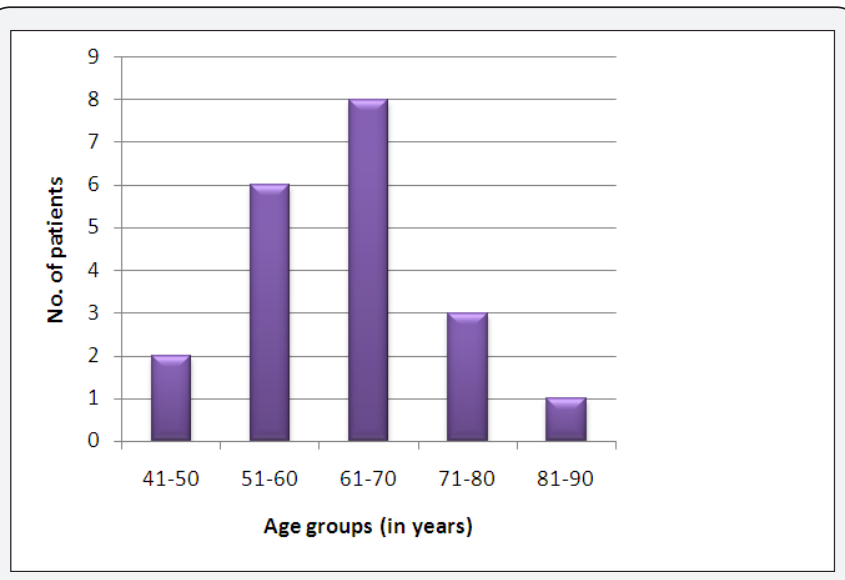

Figure 1: Age distribution.

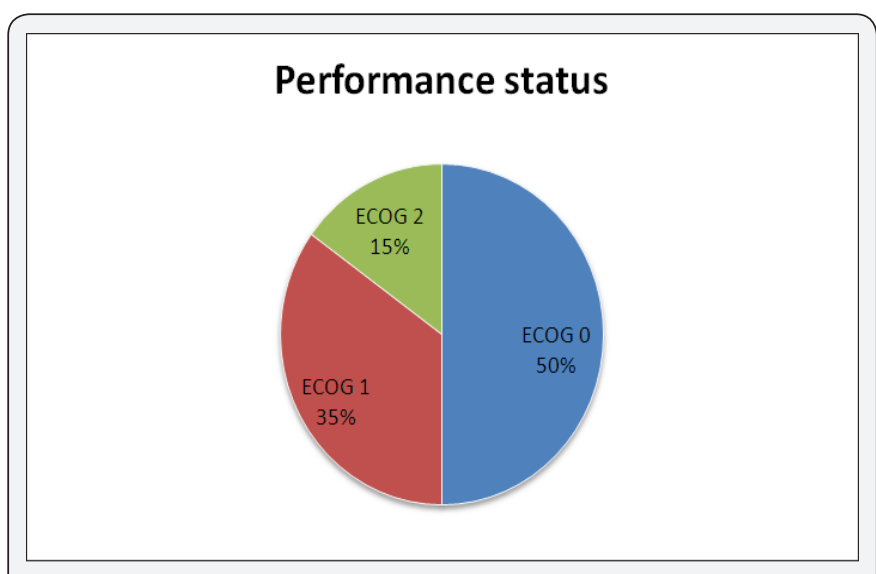

Figure 2 : Performance status. 


\section{Cancer Therapy \& Oncology International Journal}

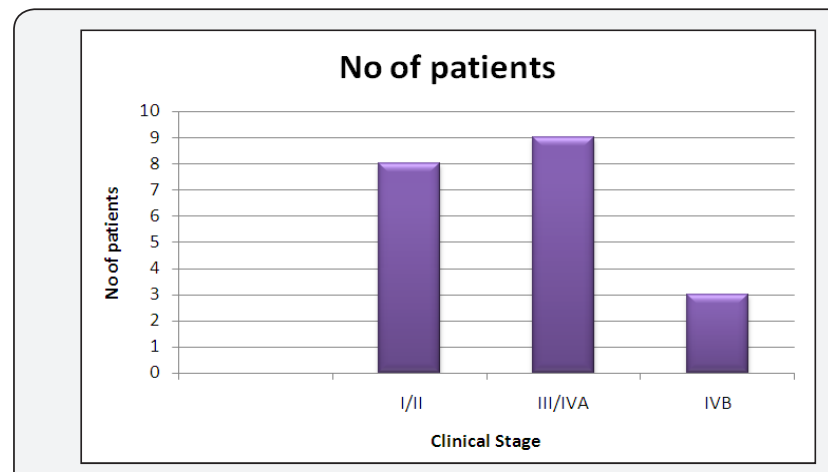

Figure 3 : Stage wise distribution of patients.

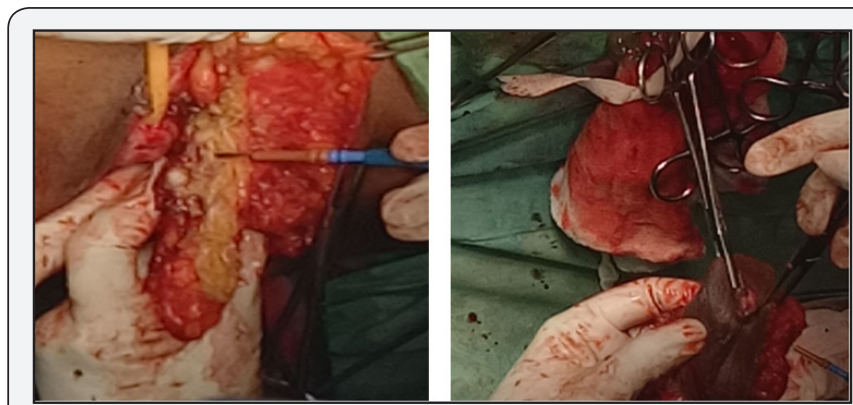

Figure 4 : Malignant vulvar mass being excised with margins to spare.
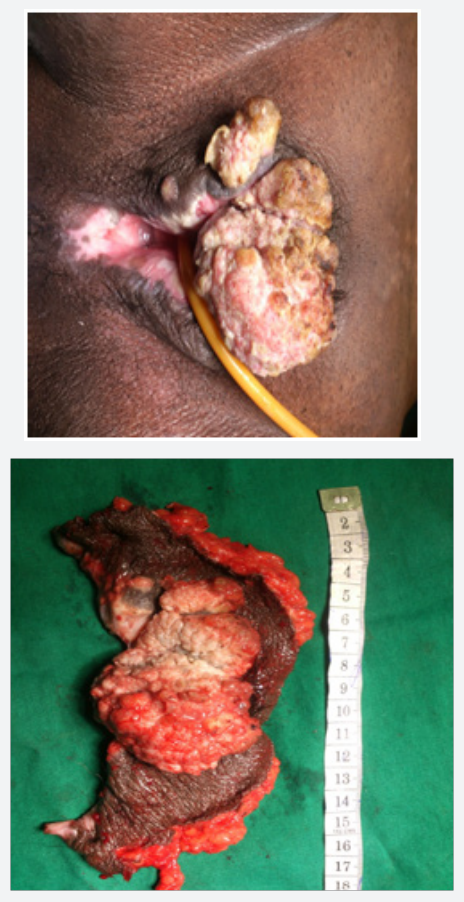
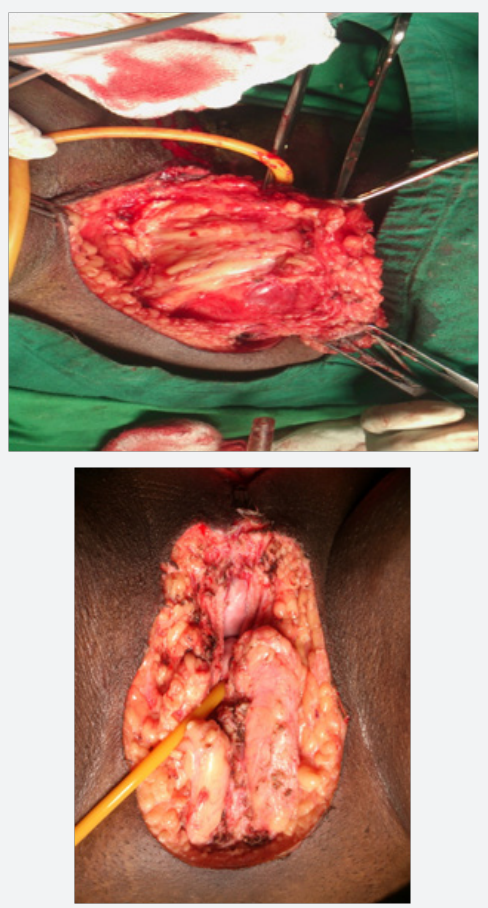
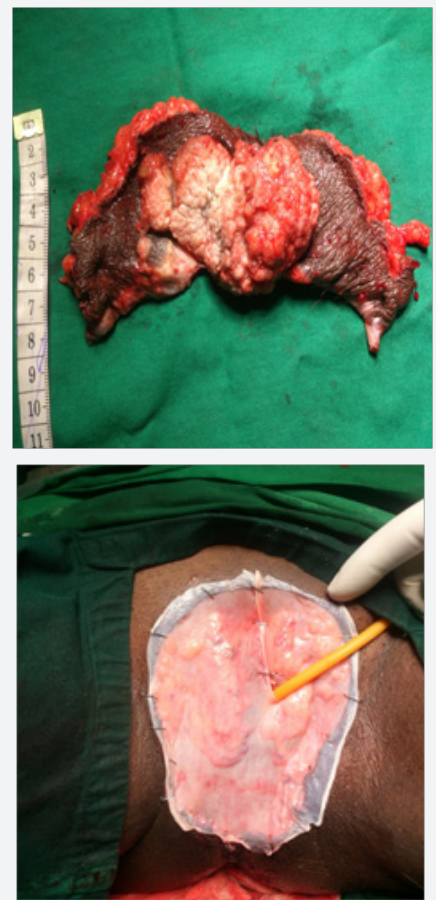

Figure 5: Images of Clinical Presentation (Proliferating mass) through dissection and grafting along with the pictures of the specimen.

Median survival of the patient of early stage disease without any nodal involvement treated only with wide local excision was not reached in our study at the time of data collection. Those treated with radical vulvectomy had a median survival of 48 months [7]. $\mathrm{CT}+\mathrm{RT}$ lead to a median survival of 28 months when advanced stage cases were included while on considering only early stage patients were considered it was not reached for this subgroup of patients. Those who were not eligible for CT+RT received only RT, results were poor with a median survival of 27 months, group inclusive of radical and palliative RT.

\section{Discussion}

In patients with HPV-negative tumors, vulvar cancer often presents as a single mass or ulcer on the labia majora or minora [8]. In HPV-positive tumors, multifocal lesions and concurrent cervical neoplasia are more common. Vulvar cancer is a relatively rare tumor, mainly seen in elderly women. The median age in various studies was ranging from 48- 65 years. In our study, the mean age was similar (63 years), and also the peak incidence was seen in the sixth and seventh decades [9]. The most common type of vulvar cancer is squamous cell carcinoma accounting for about $90 \%$ of the cases; the remaining types are Paget's disease, Bartholin's gland tumors, adenocarcinoma, and basal cell carcinoma. Okolo et al. [10] showed that $73.61 \%$ of vulvar cancers in their study were squamous cell type. In our study, all cases except were squamous cell carcinoma accounting for $100 \%$ of the cases. The management of vulvar cancer has evolved from primary surgical approach to chemo radiation.

The surgical management has become more conservative due to the well-recognized morbidity with radical vulvectomy and extensive groin dissection and psychosexual sequelae. In this study, all the early (Stage I and II) cases were primarily treated with surgery and late (Stage III and IV) cases with chemoradiation.

According to the International Federation of Gynecology and Obstetrics guidelines, treatment of micro invasive vulvar cancer (Stage Ia) is wide local excision. Groin dissection is not necessary for such lesions. In the invasive cases on the other hand groin 
dissection is recommended. For lateralized lesions unilateral groin dissection is considered sufficient but if the lesion is central then addressing bilateral inguino femoral nodes either by surgery or radiotherapy becomes mandatory. Resection of primary tumor and groin lymph node dissection is recommended using separate groin and vulvar incisions (triple incision technique) to reduce morbidity and to improve primary healing [8].

This technique was utilized in all cases with groin dissection. Appropriate groin treatment is the single most important factor in reducing mortality from early vulvar cancer [11]. It is recommended that both inguinal and femoral nodes should be removed, and appropriate dissection includes removal of at least 8-10 nodes. In our study, five cases of Stage II underwent radical vulvectomy with bilateral inguinofemoral lymphadenectomy and one had ipsilateral lymphadenectomy. All groin dissections included both inguinal and femoral lymphadenectomy. None of our cases suffered from any serious complication in the postoperative period and thus, the surgical morbidity in our cases was low.

Eleven cases in the present study were treated primarily by simple vulvectomy without inguino femoral nodal dissection. Six of these cases received adjuvant $\mathrm{RT}$ and one received chemo-radiation. These cases indicate that incomplete surgery and adjuvant RT could have been avoided if nodal dissection was complete and showed the absence of metastasis. Out of the seven cases that underwent radical or modified radical vulvectomy with inguino-femoral lymphadenectomy, only two cases needed adjuvant RT; one due to positive lymph nodes and one for inadequate surgical margin. While deciding for adjuvant treatment with RT alone or CT and RT, many factors such as age, kidney function, and comorbid conditions were also taken into consideration.

In our study, 16 cases were treated with RT (Theratron 780 and Linear accelerator Varian Trilogy) out of these 9 cases were treated with chemoradiation using concurrent cisplatin $50 \mathrm{mg}$ weekly with radiation. In advanced stages, concurrent $\mathrm{CT}$ was added to suitable patients only. A total dose of 60-70 Gy is given by combining external beam radiation and brachytherapy. 3 out of twenty treated patients were lost to follow-up. The results confirm a high survival with early stage of the disease. No patient was treated with only CT. The main drawback and limitation of our study was inadequate number of patients. Also Survival and recurrence rates could not be completely evaluated due to irregular follow up and lost to follow up cases. This is because many patients resided in remote peripheral areas. The financial constraints, lack of communication and transport facilities made the regular follow-up difficult.

\section{Conclusion}

The study concludes that the mean age of vulvar cancer is 52 years with a peak incidence in the sixth-seventh decades. Incidence is significantly high in multiparous and postmenopausal women. Surgical treatment is the best option in the early stage of disease (Stage I and II) and gives high survival rates. Complete treatment must be ensured in both surgical and chemoradiation options.

\section{Acknowledgement}

Dr. Namita M Nangia, Senior Resident, Oncology Department, Cama and Albless Hospitals, Mumbai.

\section{Reference}

1. Chhabra S, Bhavani M, Deshpande A (2014) Trends of vulvar cancer. J Obstet Gynaecol 34(2): 165-168.

2. Beller U, Quinn MA, Benedet JL, Creasman WT, Ngan HY, et al. (2006) Carcinoma of the vulva. FIGO 26th Annual Report on the Results of Treatment in Gynecological Cancer. Int J Gynaecol Obstet 95(1): S7-27.

3. N Singh, N Negi, K Srivastava, G Agarwal (2016) A cohort study of vulvar cancer over a period of 10 years and review of literature. Ind J of Cancer 53(3): 412-415

4. Koh WJ, Greer BE, Abu-Rustum NR, Campos SM, Cho KR, et al. (2017) Vulvar Cancer, Version 1.2017, NCCN Clinical Practice Guidelines in Oncology. J Natl Compr Canc Netw 15(1): 92-120.

5. ECOG (2017) ECOG performance status. USA.

6. FIGO Committee on Gynecologic Oncology (2014) FIGO staging for carcinoma of the vulva, cervix, and corpus uteri. Int J Gynaecol Obstet 125(2): 97-98.

7. Eifel PJ, Berek JS, Markman MA (2011) Cancer of the cervix, vagina, and vulva. In: DeVita VT Jr., Lawrence TS, Rosenberg SA, editors. Cancer: Principles and Practice of Oncology. $\left(9^{\text {th }}\right.$ edn $)$, Philadelphia, Lippincott Williams \& Wilkins, USA, pp. 1311-1344.

8. Hacker NF, Eifel PJ, van der Veldenc J (2012) FIGO cancer report 2012. Cancer of the vulva. Int J Gynecol Obstet 119(2): S90-S96.

9. Chitra Viswanathan, Kimberly Kirschner, Mylene Truong, Aparna Balachandran, Devine C, et al. (2013) Multimodality Imaging of Vulvar Cancer: Staging, Therapeutic Response, and Complications. AJR Am J Roentgenol 200(6): 1387-1400.

10. Okolo CA, Odubanjo MO, Awolude OA, Akang EE (2013) A Review of Vulvar and vaginal cancer in Ibadan, Nigeria. N Am J Med Sci 6(2): 7681.

11. Hacker NF (2014) Vulvar cancer. In: Berek JS \& Hacker NF (Eds.), Berek and Hacker's Gynecologic Oncology. $\left(5^{\text {th }}\right.$ edn), Lippincott Williams \& Wilkins, Philadelphia, USA, pp. 536-575. 
This work is licensed under Creative Commons Attribution 4.0 License DOI: $10.19080 /$ CTOIJ.2018.08.555747
Your next submission with Juniper Publishers will reach you the below assets

- Quality Editorial service

- Swift Peer Review

- Reprints availability

- E-prints Service

- Manuscript Podcast for convenient understanding

- Global attainment for your research

- Manuscript accessibility in different formats

( Pdf, E-pub, Full Text, Audio)

- Unceasing customer service

Track the below URL for one-step submission https://juniperpublishers.com/online-submission.php 